\title{
Echocardiographic assessment of children participating in regular sports training
}

\author{
(D) Seyma Kayali, ${ }^{1}$ (1) Fatma Tuba Yildirim² \\ ${ }^{1}$ Department of Pediatric Cardiology, University of Health Sciences, Kecioren Training and Research Hospital, Ankara, Turkey \\ ${ }^{2}$ Department of Pediatrics, Sorgun State Hospital, Yozgat, Turkey
}

\begin{abstract}
OBJECTIVE: The aim of the present study was to determine the effects of a well-controlled endurance training program on cardiac functions and structures in healthy children and to define whether training hours per week and type of sports affect the training-induced cardiovascular response.

METHODS: Echocardiographic recordings were obtained in 126 children who systematically participated in sports training for at least 1 year (study group), and the results were compared with the values obtained in 62 normal children who did not actively engage in any sports activity (control group). The two groups were comparable for age, sex, and body mass index. Study group participants were divided into two groups according to the duration of physical activity (training hours per week, $<8 \mathrm{~h}$ and $>8 \mathrm{~h}$ ) and five groups according to the cardiovascular demand of sports type. Clinical examination, resting electrocardiogram, two-dimensional, M-mode, and Doppler echocardiography were obtained in all participants.

RESULTS: Left ventricle wall dimensions, left atrial diameters, and aortic measurements were significantly higher in the study group. The mean mitral E/A ratio was also significantly higher in the training group than in untrained subjects $(p<0.001)$. Echocardiographic measurements were similar between different sports type participants in the study group. However, aortic root diameter, left atrial diameter, and left ventricle posterior wall diastolic thickness were higher in children training $>8 \mathrm{~h} /$ week than in children training $<8 \mathrm{~h} /$ week in the study group.

CONCLUSION: The present study showed that the echocardiographic parameters of children participating in regular sports training activities statistically significantly exceeded the parameters of untrained controls. These parameters were mostly dependent on the duration of training hours per week.
\end{abstract}

Keywords: Athlete's heart; children; echocardiography; sports activity.

Cite this article as: Kayali S, Yildirim FT. Echocardiographic assessment of children participating in regular sports training. North Clin Istanb 2019;6(3):236-241.

"A thlete's heart" is known as myocardial hypertro-

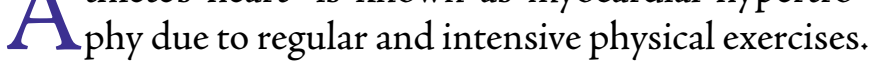
This condition is physiological, adaptive, and reversible [1]. It is also well documented that myocardial remodeling is related to the intensity and kind of sports practiced [2]. The relationship between different sports types and cardiac structures especially in adults has been investigated in many previous studies $[3,4]$. However, there are few studies in children and adolescents about the effects of sports training on cardiac functions and structures [5]. Short-term training sessions have been shown to result in significant structural and functional cardiac adaptations including increases in left ventricular posterior wall (PW) diameter and interventricular septum (IVS) thickness in children [6]. Very recently, Zdravkovic et al. investigated the electrocardiographic changes in pread-

Received: February 08, 2018 Accepted: August 29, 2018 Online: September 03, 2018

Correspondence: Dr. Seyma KAYALI. Saglik Bilimleri Universitesi, Kecioren Egitim ve Arastirma Hastanesi, Cocuk Kardiyolojisi Klinigi, Ankara, Turkey.

Tel: +90 3123569000 e-mail: ak-seyma@hotmail.com

(c) Copyright 2019 by Istanbul Provincial Directorate of Health - Available online at www.northclinist.com 
olescent footballers and reported significant differences between the footballers and control group regarding $\mathrm{P}$-wave, $\mathrm{S}$-wave, and $\mathrm{R}$-wave voltages; wave duration; and QTc interval duration that were considered as the electrocardiogram (ECG) pattern of left ventricle (LV) remodeling since those athletes did not develop any adverse cardiac events in the 6-year follow-up [7]. In that aspect, it is important to determine the impact of regular exercise and the remodeling period on children's heart that is still in the maturation period.

The aim of the present study was to determine the effects of regular exercise on the child's heart and to define whether training hours per week or type of sports affects the training-induced cardiovascular response in training children.

\section{MATERIALS AND METHODS}

This was a prospective, case-control study conducted from February 2016 to December 2016 on 126 children who systematically participated in sports training for at least 1 year (study group) and 62 normal children who did not actively engage in sports (control group).

Children with congenital heart disease and arrhythmia-associated chronic diseases (e.g., obesity, hypertension, and diabetes mellitus) and children who were under regular medications were excluded from the study. Study group participants were divided into two groups according to the duration of physical activity (training hours per week, $<8 \mathrm{~h}$ and $>8 \mathrm{~h}$ ) and five groups according to the cardiovascular demand of sports type (2). This classification allows classifying sports type according to cardiovascular demand. The lowest total cardiovascular demands (cardiac output and blood pressure) are shown in green and the highest in red; blue, yellow, and orange depict low moderate, moderate, and high moderate total cardiovascular demands (2) (Fig. 1).

All participants had clinical examination, resting ECG, two-dimensional (2D), M-mode, and Doppler echocardiography.

\section{Echocardiographic Examination}

Echocardiography was performed using the Vivid 3 (General Electric, USA) echocardiography by the aid of $3 \mathrm{MHz}$ probes. All echocardiographic examinations were performed by one experienced pediatric cardiologist who was blinded to the training status of the participants to avoid inter-observer variability, from the long

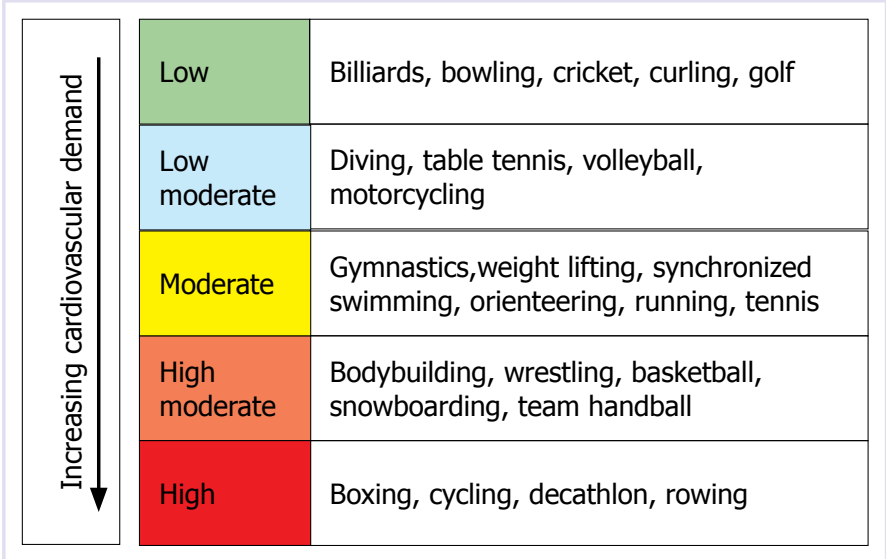

FIGURE 1. Classification of sports according to cardiovascular demand.

axis view and following the American Heart Association echo guidelines [8]. The standard LV 2D parameters were obtained at rest. The basal $2 \mathrm{D}$ systo-diastolic and Doppler parameters; IVS and PW thickness; LV end-diastolic diameter (LVEDd), LV end-systolic diameter (LVESd), left atrium (LA), aortic root (AR), and ascending aorta (AA) dimensions; pulse wave Doppler transmitral flow $\mathrm{E}$-wave and $\mathrm{A}$-wave (E/A ratio) were recorded. Mitral E/A ratio was used as a diastolic index of the LV. The assessment of the systolic function of the myocardium was made by the measurement of the ejection fraction (EF\%) that was obtained according to the formula $\left[(\mathrm{LVEDd})^{3}-(\mathrm{LVESd})^{3} /(\mathrm{LVEDd}) 3\right]^{*} 100$ and the percentage of the shortening of the LV (FS\%) (LVEDd-LVESd/LVEDd*100).

\section{Statistical Analyses}

Statistical analyses were performed by the SPSS 22 for Windows software (IBM SPSS Statistics for Windows, Version 22.0. Armonk, NY,USA). All data were expressed as mean $\pm \mathrm{SD}$. The echocardiographic variables were compared between the study and control groups by the Student's t-test and Mann-Whitney U test. The study group comparison according to sports type was performed by Kruskal-Wallis variance analysis test. A p value $<0.05$ was regarded as statistically significant.

\section{Ethical Approval}

All study procedures were approved by the ethics committee of a tertiary center (2012-KAEK-15/1322) according to the Declaration of Helsinki. Written informed consent was obtained from all subjects and their parents. 


\begin{tabular}{|c|c|c|c|}
\hline & $\begin{array}{l}\text { Study group } \\
\qquad(\mathrm{n}=126)\end{array}$ & $\begin{array}{l}\text { Control group } \\
\qquad(\mathrm{n}=62)\end{array}$ & $\mathrm{p}$ \\
\hline Age (months) & $162.3 \pm 31.9$ & $162.3 \pm 31.1$ & 0.99 \\
\hline Height (cm) & $160.7 \pm 16.4$ & $157.4 \pm 13.3$ & 0.16 \\
\hline Weight (kg) & $53.4 \pm 16.9$ & $50.3 \pm 12.5$ & 0.20 \\
\hline $\mathrm{BMI}\left(\mathrm{kg} / \mathrm{m}^{2}\right)$ & $20.1 \pm 3.6$ & $20 \pm 3.18$ & 0.80 \\
\hline $\mathrm{SBP}(\mathrm{mmHg})$ & $113.6 \pm 10.4$ & $112.1 \pm 10.3$ & 0.36 \\
\hline $\mathrm{DBP}(\mathrm{mmHg})$ & $63.2 \pm 8.2$ & $65 \pm 7.4$ & 0.15 \\
\hline $\mathrm{HR}$ (bpm) & $83.9 \pm 13.3$ & $91.8 \pm 14.2$ & 0.01 \\
\hline
\end{tabular}

BMI: Body mass index; SBP: Systolic blood pressure; DBP: Diastolic blood pressure; HR: Heart rate.

TABLE 2. Comparison of echocardiographic parameters among the groups

\begin{tabular}{lccc} 
& $\begin{array}{c}\text { Study group } \\
(n=126)\end{array}$ & $\begin{array}{c}\text { Control group } \\
(n=62)\end{array}$ & $p$ \\
\hline AR mm & $22.6 \pm 3.5$ & $21.5 \pm 2.6$ & 0.02 \\
AA mm & $21.1 \pm 2.8$ & $20.3 \pm 2.1$ & 0.03 \\
LAD mm & $27.2 \pm 4.1$ & $25.2 \pm 3.4$ & 0.01 \\
EF \% & $71.8 \pm 5.6$ & $71.2 \pm 6.2$ & 0.49 \\
FS\% & $41 \pm 4.8$ & $40.5 \pm 5.2$ & 0.55 \\
LVEDd mm & $43 \pm 5.7$ & $42.8 \pm 4$ & 0.77 \\
LVESd mm & $25.3 \pm 4.4$ & $25.1 \pm 3.9$ & 0.79 \\
IVSD mm & $10.5 \pm 2.2$ & $9.2 \pm 2.1$ & 0.01 \\
IVSS mm & $13.5 \pm 2.4$ & $12.1 \pm 2.1$ & 0.01 \\
LPWd mm & $9.6 \pm 2.2$ & $7.8 \pm 1.7$ & 0.01 \\
LPWs mm & $15.3 \pm 3.1$ & $13.3 \pm 3.7$ & 0.01 \\
Mitral E/A & $1.9 \pm 0.2$ & $1.6 \pm 0.2$ & 0.01 \\
\hline AR: Aodtc rot; AA: As & &
\end{tabular}

AR: Aortic root; AA: Asendan aorta; LAD: Left atrial diameter; EF: Ejection fraction; FS: Shortening fraction; LVEDd: Left ventricle end diastolic diameter; LVESd: Left ventricle end sistolic diameter; IVSD: Interventriculer septum in diastole; IVSS: Interventriculer septum in systole; LPWD: left ventricle posterior wall thickness in diastole; LPWs: left ventricle posterior wall thickness in systole.

\section{RESULTS}

Demographic and general characteristics of the study participants are defined in Table 1 . There were no statistically significant differences between the study and control groups regarding age, gender, height, weight, and body mass index (BMI). Resting systolic and diastolic blood pressures were also similar. Heart rate was lower

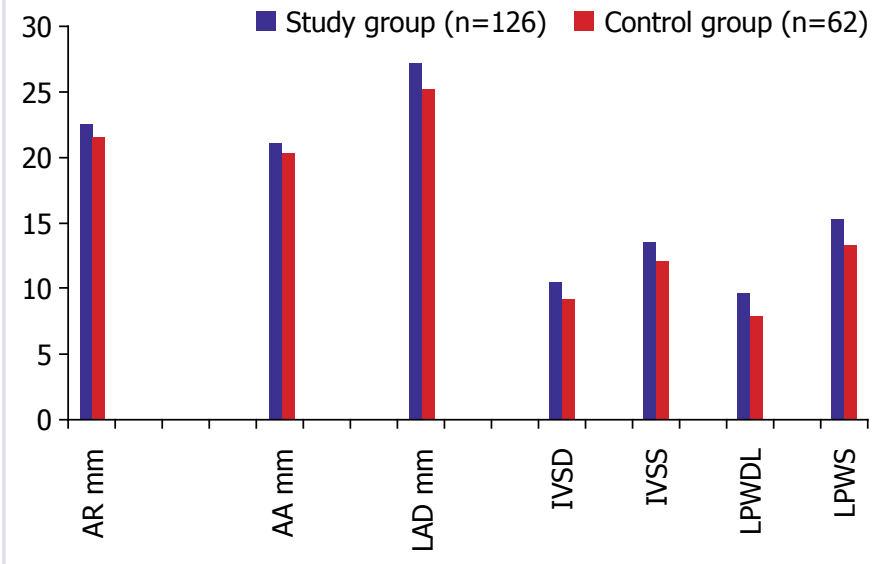

FIGURE2. Alterations in some echocardiographic parameters among the two groups. AR: Aortic root; AA: Asendan aorta; IVSD: Interventriculer septum diameter in diastole; IVSS: Interventriculer septum diameter in systole; LPWD: Left ventricle posterior wall diameter in diastole; LPWS: Left ventricle posterior wall diameter in systole.

in the study group $(p=0.01)$ (Table 1$)$.

The echocardiographic measurements of aortic dimensions ( $A R$ and $A A$ ) were significantly higher in the study group $(p=0.02$ and $p=0.03$, respectively). Echocardiographic analyses of the left heart showed that the values of the LA, LV PW thickness in diastole (LVPWd), and LV PW thickness in systole (LVPWs) were statistically significantly increased in the study group ( $p=0.01)$ (Table 2, Fig. 2).

The values of interventricular septum diameter in systole (IVSs), interventricular septum diameter in diastole (IVSd), and mitral E/A ratio were also found to be higher in the study group $(p=0.01)$.

Contractibility parameters (EF\% and FS\%) and LVEDd and LVESd were higher in the study group, but the differences between the two groups were not statistically significant.

When the study group was assessed according to training hours per week, all echocardiographic measurements were higher in the group training $>8 \mathrm{~h}$. However, only measurements of LVPWd, LA, and AR were statistically significantly higher in the subgroup training $>8 \mathrm{~h}$ than in the study subgroup training $<8 \mathrm{~h}$ $(\mathrm{p}=0.01)$ (Table 3$)$.

When the study group participants were assessed according to sports type classification, there were 5 participants in green, 7 in blue, 56 in yellow, 15 in orange, and 43 in red areas. Any statistically significant differences 
TABLE 3. Echocardiographic measurements of groups according to training hours per week

\begin{tabular}{lccc} 
& $\begin{array}{c}\text { Control group } \\
(\mathrm{n}=62)\end{array}$ & $\begin{array}{c}\text { Less than } \\
8 \text { hours a week }\end{array}$ & $\begin{array}{c}\text { More than } \\
8 \text { hours a week }\end{array}$ \\
\hline AR mm & $21.5 \pm 2.6$ & $22.1 \pm 3.4$ & $24.0 \pm 3.5$ \\
AA mm & $20.3 \pm 2.1$ & $21.0 \pm 2.9$ & $21.7 \pm 2.4$ \\
LAD mm & $25.2 \pm 3.4$ & $26.8 \pm 3.8$ & $29.0 \pm 4.4$ \\
EF \% & $71.2 \pm 6.2$ & $71.8 \pm 5.3$ & $71.9 \pm 6.5$ \\
FS\% & $40.5 \pm 5.2$ & $41.1 \pm 4.5$ & $41.7 \pm 5.8$ \\
LVEDd mm & $42.8 \pm 4.0$ & $43.3 \pm 5.5$ & $43.4 \pm 6.8$ \\
LVESd mm & $25.1 \pm 3.9$ & $25.2 \pm 4.4$ & $25.5 \pm 4.6$ \\
IVSD mm & $9.2 \pm 2.1$ & $10.3 \pm 2.3$ & $10.8 \pm 2.1$ \\
IVSS mm & $12.1 \pm 2.1$ & $13.3 \pm 2.5$ & $14.3 \pm 2.5$ \\
LPWd mm & $7.8 \pm 1.7$ & $9.3 \pm 1.9$ & $10.5 \pm 2.8$ \\
LPW mm & $13.3 \pm 3.7$ & $15.2 \pm 2.7$ & $15.7 \pm 3.9$ \\
Mitral E/A & $1.6 \pm 0.2$ & $1.9 \pm 0.2$ & $1.9 \pm 0.2$ \\
\hline
\end{tabular}

AR: Aortic root; AA: Asendan aorta; LAD: Left atrial diameter; EF: Ejection fraction; FS: Shortening fraction; LVEDd: Left ventricle end diastolic diameter; LVESd: Left ventricle end sistolic diameter; IVSD: Interventriculer septum in diastole; IVSS: Interventriculer septum in systole; LPWD: Left ventricle posterior wall thickness in diastole; LPWs: Left ventricle posterior wall thickness in systole.

regarding echocardiographic parameters were not determined between these subgroups $(p>0.05)$.

\section{DISCUSSION}

Currently, the adaptation of the heart to training has been largely studied in adults. However, there are still limited data about the adaptation of children's heart to training that is still in the maturation period. In the present study, we determined that regular exercise training induces cardiovascular changes in children. First, in the present study, heart rate was determined to be statistically significantly lower in the study group. It is a well-known fact that long term endurance training is associated with cardiac neural remodeling in favor of cardioprotective vagal mechanisms, resulting in resting bradycardia [9]. Different pediatric and adult studies showed that athletes were having significantly greater prevalence of sinus bradycardia than non-athletes $[5,10]$. Similarly, Sharma et al. evaluated the electrocardiographic alterations in 1000 junior athletes with a mean age of 15.7 years and reported that athletes have a significantly higher prevalence of sinus bradycardia and sinus arrhythmia than non-athletes with significantly prolonged PR interval and QRS and QT durations [11]. Although we did not evaluate the electrocardiographic changes, we also determined that regular training in children is associated with lower heart rates. We believe that this alteration is associated with increased vagal tone and increased cardiac size as reported in previous studies [11].

Cardiac output increases up to $30 \mathrm{~L} / \mathrm{min}$ to $40 \mathrm{~L} /$ min with a positive linear relationship to the intensity of the activity during exercise in trained subjects [12]. However, it may eventually lead to increased hemodynamic insult and mechanical stress on the great vascular structures and cardiac chambers. Associated with increased blood flow, hemodynamic insult, or increased shear stress during exercise, dilatation of AR and AA could be observed due to medial degeneration of the vessel layer [12]. Ventricular systolic EF was also determined to be increased in training children [6]. Second, in the present study, the echocardiographic measurements of aortic dimensions (AR and AA) were significantly higher in the study group $(p=0.02$ and $p=0.03$, respectively). Similarly, it was reported recently that aortic dilation and subsequently, thoracic aorta aneurysms may be an occupational disease due to the nature of some professions including athletes [13]. The compensation procedure for this elevated cardiac output and overload of the flowing blood results in the increase of not only the diameter of the aorta but also the diameter of cardiac chambers and relative wall thickness $[14,15]$.

Third, in the present study, LVPWd, LVPWs, IVSd, and IVSs were statistically significantly higher in the study group, whereas there were no differences in LVEDd and LVESd measurements. However, an increase in the left ventricular end-diastolic diameter associated with an improvement in diastolic function after training compared with the resting data was previously reported [16]. The two main types of an athlete's heart were described according to the type of exercise as dynamic or static: Eccentric hypertrophy (increase in cavity diameter and wall thickness) and concentric hypertrophy (increase in wall diameter without any change on cavity size). [17]. Therefore, individuals with an athlete's heart could exhibit further cardiac adaptation in response to different trainings $[18,19]$. In that aspect in the evaluation of different results reported in the literature about the effects of training on cardiac functions, the type of training should be considered.

Our findings are due to heterogeneity of the study group and also support further cardiac adaptation ac- 
cording to sports type. Similarly, Venkunas et al. did not observe any significant differences in the end-diastolic diameter between the athletic and control groups [20].

Fourth, one of the significant findings to be discussed was greater left atrial diameter measurement in the study group than that in the control group. The increase of the LA is common in athletes due to increased pressure in the cavity during exercise. Toufan et al. recently reported that LA diameters are increased as a left atrial remodeling in response to prolonged duration of regular endurance sports [19].

Fifth, regarding the diastolic function, there was a significant increase of the $\mathrm{E} / \mathrm{A}$ ratio in the study group. In several studies related to diastolic function in athletes, an increase in $\mathrm{E}$-wave velocity and an increase in the $\mathrm{E} / \mathrm{A}$ ratio have been observed from different sports $[20,21]$. These findings are suggestive of a supernormal diastolic function mediated by a combination of improved initial ventricular relaxation and increased left ventricular compliance.

When the study group was examined in itself according to training hours, statistically significant increases in LVPWd, LA, and AR were detected in participants training $>8 \mathrm{~h} /$ week. Similarly, a study in which participants were divided into groups according to training hours per week reported that IVS thickness, end-diastolic diameter, and left ventricular mass were significantly higher in athletes whose training exceeded $8 \mathrm{~h} /$ week than in controls [22]. Agrebi et al. reported that among children who were having a regular training for handball, LVEDd, LVESd, LA, AR, and LV mass are all significantly lower in younger children than in older ones and adults [23]. This finding was suggested to be associated with the duration of prior practice and early cardiac remodeling. We did not subgroup the patients regarding their ages, but this data also supports our finding that with an increase in training time, LVEDd, LVESd, LA, $\mathrm{AR}$, and LV mass were increasing.

It is a well-known fact that cardiovascular response to sports is associated with the type and duration of exercise $[24,25]$. Since, our study group was so heterogeneous when classified according to sports type, no difference could be determined between the groups regarding echocardiographic parameters.

We did not determine any significant alterations in systolic blood pressure between the study and control groups. In a recent study, Tan et al. [26] reported a decrease in both systolic blood pressure and heart rate of obese children with exercise training. We did not deter- mine the BMIs of children in the present study, which may be the topic of future investigations.

There are some limitations of the present study that should be defined. First is the low number of study participants, and second is the assessment of only shortterm records. Moreover, in a recent study, D'Ascenzi et al. determined an increase in right ventricle size after 5 months of intensive training in children without an alteration in its functions that was suggested as a part of the remodeling period [27].

\section{Conclusion}

The principal aspect of the present study is the confirmation of the presence of sports-related cardiovascular changes in children similar to adults.

These parameters were mostly dependent on the duration of training hours per week.

Further prospective, larger, long-term follow-up studies are warranted to understand the importance of especially sports type on cardiovascular response.

Ethics Committee Approval: This study was approved by the ethic committe of Health Sciences University Kecioren Training and Research Hospital (Number: 2012-KAEK-15/1322).

Conflict of Interest: The authors declare no conflict of interest.

Financial Disclosure: The authors declared that this study has received no financial support.

Authorship Contributions: Concept - SK; Design - SK; Supervision - SK; Materials - SK, FTY; Data collection and/or processing - SK, FTY; Analysis and/or interpretation - SK, FTY; Writing - SK; Critical review - SK, FTY.

\section{REFERENCES}

1. De Luca A, Stefani L, Pedrizzetti G, Pedri S, Galanti G. The effect of exercise training on left ventricular function in young elite athletes. Cardiovasc Ultrasound 2011;9:27. [CrossRef]

2. Mitchell JH, Haskell W, Snell P, Van Camp SP. Task Force 8: classification of sports. J Am Coll Cardiol 2005;45:1364-7. [CrossRef]

3. Rawlins J, Bhan A, Sharma S. Left ventricular hypertrophy in athletes. Eur J Echocardiogr 2009;10:350-6. [CrossRef]

4. Weiner RB, DeLuca JR, Wang F, Lin J, Wasfy MM, Berkstresser B, et al. Exercise-Induced Left Ventricular Remodeling Among Competitive Athletes: A Phasic Phenomenon. Circ Cardiovasc Imaging 2015; pii: e003651. [CrossRef]

5. McClean G, Riding NR, Ardern CL, Farooq A, Pieles GE, Watt V, et al. Electrical and structural adaptations of the paediatric athlete's heart: a systematicreview with meta-analysis. Br J Sports Med 2018;52:230.

6. Krustrup P, Hansen PR, Nielsen CM, Larsen MN, Randers MB, Manniche V, et al. Structural and functional cardiac adaptations to a 10-week school-based football intervention for 9-10-year-old children. 
Scand J Med Sci Sports 2014;24 Suppl 1:4-9. [CrossRef]

7. Zdravkovic M, Milovanovic B, Hinic S, Soldatovic I, Durmic T, Koracevic $\mathrm{G}$, et al. Correlation between ECG changes and early left ventricular remodeling in preadolescent footballers. Physiol Int 2017;104:42-51.

8. Bonow RO, Carabello BA, Chatterjee K, de Leon AC Jr, Faxon DP, Freed MD, et al. ACC/AHA 2006 guidelines for the management of patients with valvular heart disease: a report of the American College of Cardiology/American Heart Association Task Forceon Practice Guidelines (writing Committee to Revise the 1998 guidelines for the management of patients with valvular heart disease) developed in collaboration with the Society of Cardiovascular Anesthesiologists endorsed by the Society for Cardiovascular Angiography and Interventions and the Society of Thoracic Surgeons. J Am Coll Cardiol 2006;48:e1-148.

9. Sala R, Malacarne M, Tosi F, Benzi M, Solaro N, Tamorri S, et al. May a unitary autonomic index help assess autonomic cardiac regulation in elite athletes? Preliminary observations on the national Italian Olympic committee team. J Sports Med Phys Fitness 2017;57:1702-10.

10. Stanley J, Peake JM, Buchheit M. Cardiac parasympathetic reactivation following exercise: implications for trainingprescription. Sports Med 2013;43:1259-77. [CrossRef]

11. Sharma S, Whyte G, Elliott P, Padula M, Kaushal R, Mahon N, et al. Electrocardiographic changes in 1000 highly trained junior elite athletes. Br J Sports Med 1999;33:319-24. [CrossRef]

12. Warburton DE, Haykowsky MJ, Quinney HA, Blackmore D, Teo KK, Humen DP. Myocardial response to incremental exercise in endurancetrained athletes: influence of heart rate, contractility and the Frank-Starling effect. Exp Physiol 2002;87:613-22. [CrossRef]

13. Okamoto RJ, Xu H, Kouchoukos NT, Moon MR, Sundt TM 3rd. The influence of mechanical properties on wall stress and distensibility of the dilated ascending aorta. J Thorac Cardiovasc Surg 2003;126:84250. [CrossRef]

14. Aparci M, Erdal M, Isilak Z, Yalcin M, Uz O, Arslan Z, et al. Enlargement of the aorta: An occupational disease? Exp Clin Cardiol 2013;18:93-7.

15. Pluim BM, Zwinderman AH, van der Laarse A, van der Wall EE. The athlete's heart. A meta-analysis of cardiac structure and function. Circulation 2000;101:336-44. [CrossRef]

16. Obert P, Mandigouts S, Nottin S, Vinet A, N'Guyen LD, Lecoq AM.
Cardiovascular responses to endurance training in children: effect of gender. Eur J Clin Invest 2003;33:199-208. [CrossRef]

17. Morganroth J, Maron BJ, Henry WL, Epstein SE. Comparative left ventricular dimensions in trained athletes. Ann Intern Med 1975;82:5214. [CrossRef]

18. Naylor LH, George K, O'Driscoll G, Green DJ. The athlete's heart: a contemporary appraisal of the 'Morganroth hypothesis'. Sports Med 2008;38:69-90. [CrossRef]

19. Toufan M, Kazemi B, Akbarzadeh F, Ataei A, Khalili M. Assessment of electrocardiography, echocardiography, and heart rate variability in dynamic and static type athletes. Int J Gen Med 2012;5:655-60. [CrossRef]

20. Venckunas T, Lionikas A, Marcinkeviciene JE, Raugaliene R, Alekrinskis A, Stasiulis A. Echocardiographic parameters in athletes of different sports. J Sports Sci Med 2008;7:151-6.

21. Moro AS, Okoshi MP, Padovani CR, Okoshi K. Doppler echocardiography in athletes from different sports. Med Sci Monit 2013;19:18793. [CrossRef]

22. Bartkeviciene A, Dalia B. Changes in morphometric parameters and function of left ventricle in child and adolescent athletes. Medicina (Kaunas) 2007;43:251-8. [CrossRef]

23. Agrebi B, Tkatchuk V, Hlila N, Mouelhi E, Belhani A. Impact of specific training and competition on myocardial structure and function in different age ranges of male handball players. PLoS One 2015;10:e0143609.

24. Prakken NH, Velthuis BK, Teske AJ, Mosterd A, Mali WP, Cramer MJ. Cardiac MRI reference values for athletes and nonathletes corrected for body surface area, training hours/week and sex. Eur J Cardiovasc Prev Rehabil 2010;17:198-203. [CrossRef]

25. Galanti G, Stefani L, Mascherini G, Di Tante V, Toncelli L. Left ventricular remodeling and the athlete's heart, irrespective of quality load training. Cardiovasc Ultrasound 2016;14:46. [CrossRef]

26. Tan S, Chen C, Sui M, Xue L, Wang J. Exercise Training Improved Body Composition,Cardiovascular Function, and Physical Fitness of 5-Year-Old Children With Obesity or Normal Body Mass. Pediatr Exerc Sci 2017;29:245-53. [CrossRef]

27. D’Ascenzi F, Pelliccia A, Valentini F, Malandrino A, Natali BM, Barbati $\mathrm{R}$, et al. Training-induced right ventricular remodelling in pre-adolescent endurance athletes: The athlete's heart in children. Int J Cardiol 2017;236:270-5. [CrossRef] 